\title{
Surface ionization detection of amine containing drugs in backgrounds of pharmaceuticals and extender materials
}

\author{
A. Hackner ${ }^{1}$, S. Beer ${ }^{1}$, G. Müller ${ }^{1}$, E. Biavardi' ${ }^{2}$, E. Dalcanale ${ }^{2}$ \\ ${ }^{1}$ EADS, Innovation Works, P.O. BOX 81663 Munich, Germany \\ angelika.hackner@eads.com \\ ${ }^{2}$ Consorzio Interuniversitario Nazionale Scienze e Tecnologie dei Materiali, Parma, Italy
}

\begin{abstract}
This work is concerned with the development of a miniaturized detection system for amine containing illicit drugs. The detection involves flash desorption of collected solid particles and surface ionization (SI) of the vaporized components. In previous works we have shown that SI gas detection is very sensitive towards amines and relatively insensitive towards other hydrocarbonspecies and water vapour [1,2]. In the present contribution we concentrate on the discrimination between illicit drugs, on the one hand, and extender materials and pharmaceuticals, on the other hand. In our presentation it will be demonstrated that SI detection is able to detect amine containing drugs in large backgrounds of pharmaceuticals and extender materials, which normally come along in street samples of illicit drugs.
\end{abstract}

Key words: Surface ionization detection, amine containing illicit drugs, flash desorption of solid particles.

\section{Introduction}

The illegal trade of drugs is a worldwide societal problem, associated with illegal business and organized crime. Drug abuse is responsible for crimes like shoplifting, burglaries and robberies [3] due to the high price of strongly addictive drugs. The world's largest illicit drug product in volume terms - is cannabis. Second is cocaine, followed by heroin. Amphetamine-type stimulants (ATS) production seems to range at a comparable level with heroin [4]. The drugs cocaine, heroin and amphetamines have in common that they all contain amino groups attached to their hydrocarbon skeletons, which makes them detectable by means of surface ionisation (SI). In street samples these drugs are extended with food-stuff filler materials and also common pharmaceuticals, some of them also containing amine functional groups. In practical searches, the challenge is to select illegal drugs from harmless and legal extender substances.

Surface ionization detectors are sensitive, selective and very fast responding devices, which feature small size, light weight, and which are easy to use. SI detectors therefore offer a clear potential for becoming routine tools for the in-field use by police and customs officers.

\section{Flash evaporation detection of illicit drugs, potential drug additives and pharmaceuticals}

Illicit drugs usually abound in salt form as well as mixed with various drug additives and pharmaceutics. Before detection these substances need to be collected and transformed into detectable vapours using flash evaporation. Surface ionization detection involves adsorption of the vaporized compounds on a heated emitter surface, ionisation by means of electron transfer to the adsorbent solid and extraction of the positive analyte ions from the emitter surface towards a negatively biased counter electrode. Drugs containing amine functional groups feature very low ionisation energies and are therefore particularly easy to ionise. Usually aminecontaining substances easily split off $\mathrm{H}$ atoms, forming $(\mathrm{M}-\mathrm{H})$ radicals, which can easily be collected in the form of $(\mathrm{M}-\mathrm{H})^{+}$ion currents $[5,6]$.

In our investigations we have concentrated on Ephedrine Hydrochloride as surrogate for drugs. Representatives of pharmaceuticals and extender materials were lactose, paracetamol, caffeine and atropine. A SI detector, operated at $310^{\circ} \mathrm{C}$, was directly positioned above a desorber pad, which contained the collected solid samples (1-3mg). For detection, a heat stamp, pre-heated to $180^{\circ} \mathrm{C}$, was brought into 
contact with the desorber pad to produce a flash of detectable vapors. In the experiment shown in Figure 1, small quantities of drug and interfering substances were put onto desorber pads and desorbed into the SI detector. The SI detector was configured in a way to allow for simultaneous readings of the SI current and the emitter temperature. Our results show that a hot air plume is generated whenever a flash evaporation event takes place, a SI response, however, is only observed when the drug substitute Ephedrine $\mathrm{HCl}$ and the extender material atropine are evaporated. Both substances contain amine functional groups and therefore are detectable via SI. Not detectable are the extender materials Lactose, which does not contain any amino group, and Caffeine and Paracetamol, which both contain amino groups incorporated into hetero rings. Response and recovery times are very fast, in the order seconds, limited only by the dynamics of the evaporation events.

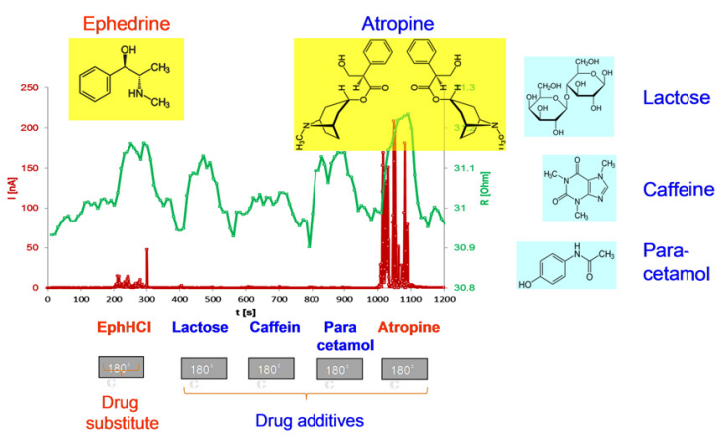

Fig. 1. SI currents (red curve) in response to a drug substitute and various pharmaceutical and extender materials (1mg each). The SI emitter was a thin film of $\mathrm{Fe}_{2} \mathrm{O}_{3}$ heated to $310^{\circ} \mathrm{C}$. The green curve shows the variation of the emitter temperature as the different substances were flash evaporated into the SI detector.

\section{Summary}

SI gas detection combined with flash evaporation is an effective tool for the in-field detection of illicit drugs. SI drug detection instruments are light-weight and small, low cost and user friendly, which makes them ideal for the in-field use by police and customs officers. SI is sensitive to illicit drugs but insensitive to a range of pharmaceuticals and extender materials which come along with street samples of illicit drugs. Temperatureprogrammed desorption techniques will further improve the selectivity with regard to aminecontaining extender substances.

\section{Acknowledgements}

The authors kindly acknowledge the financial support under theFP7 projects "S3" (FP7-NMP2009-247768) and "DIRAC" (FP7-SEC-2009242309).

\section{References}

[1] C. Oberhüttinger, A. Hackmer, G. Müller, M. Stutzmann, On the temperature dependence of the resistive and surface ionization response of metal oxide gas sensing layers, Sensors and Actuators B:Chemical Vol./Iss.: 156,2 (2011); doi: 10.1018/j.snb.2011.01.069

[2] Angelika Hackner, Sebastian Beer, Gerhard Müller, Thomas Fischer, Sianjay Mathur, Surface ionization detection of amphetamine-type illicit drugs, Sensors and Actuattors B: ChemicalVol./Iss.:162,1,209-215 (2012);ISSN 0925-4005

[3] Home office Online report, The illegal drug trade in the United Kingdom, (2007); ISBN: 9781 847255500

[4] United Nations Office, World Drug Report (2011); ISBN:978-92-1-148262-1

[5] U.K. Rasulev, U. Khasanov, V.V. Palitcin, Surface-ionization methods and devices of indication and identification of nitrogen-containing base molecules, J. Chromatogr. A 896, 3-18 (2000); PMID: 11093635

[6] T. Fujii, T. Kitai, Surface ionization mass spectrometry of organic compounds: nitrogencontaining aliphatic organic compounds, Int. J. Mass Spectrom. Ion Processes 71, 129-140 (1986); doi: 10.1016/0168-1176/87/83001-x 